\title{
Serum Concentrations of the Type I and III Procollagen Propeptides as Biochemical Markers of Growth Velocity in Healthy Infants and Children and in Children with Growth Disorders
}

\author{
PREMILA TRIVEDI, JUHA RISTELI, LEILA RISTELI, PETER C. HINDMARSH, \\ CHARLES G. D. BROOK, AND ALEX P. MOWAT \\ Department of Child Health, King's College Hospital, Denmark Hill, London, SE5 8RS, United Kingdom \\ [P.T., A.P.M.]; Collagen Research Unit, Departments of Medical Biochemistry and Clinical Chemistry, \\ University of Oulu, Oulu, Finland [J.R., L.R.]; and Endocrine Unit, Middlesex Hospital, \\ Mortimer Street, London, WIN 8AA, United Kingdom [P.C.H., C.G.D.B.]
}

\begin{abstract}
The reproducibility and specificity of a new, rapid, simple RIA for measuring the concentration of the soluble carboxypropeptide of type I procollagen (PICP) in serum was confirmed. Serum PICP was determined in 442 healthy Caucasian subjects ranging in age from 3 wk to 18 y. Highest PICP values (mean \pm SD: $2200 \pm 350 \mu \mathrm{g} / \mathrm{L}$ ) occurred in infants less than 3 mo of age, falling by $70 \%$ at $2 \mathrm{y}$ and by an additional $10 \%$ at $4 \mathrm{y}$. There was no significant change in serum PICP between 4 and $16 \mathrm{y}$ of age $(330 \pm 130 \mu \mathrm{g} / \mathrm{L})$, but a decrease to adult levels of $<160 \mu \mathrm{g} / \mathrm{L}$ occurred by $18 \mathrm{y}$. In 76 children with growth disorders, serum PICP was related to linear growth velocity $(p<0.001)$, although there were no significant differences in PICP among the 38 children with growth hormone insufficiency, the 21 short children with no endocrinologic abnormality, or the 17 tall children. All 15 prepubertal children treated with growth hormone for 3 mo showed significant increases in both growth velocity and serum PICP, with a significant relationship $(p<0.01)$ between the degree of increases. The rise in serum PICP at 3 mo (but not baseline PICP values) predicted the increase in growth velocity after $1 \mathrm{y}$ of treatment. Similar changes were observed in the concentration of the aminopropeptide of type III procollagen, except that serum aminopropeptide of type III procollagen showed a definite increase during puberty and a wider spread of values in growth disorders. We conclude that measuring serum PICP by the new, reproducible assay reflects height velocity in prepubertal children and may be a useful biochemical means of monitoring growth rates. (Pediatr Res 30: 276-280, 1991)
\end{abstract}

\section{Abbreviations}

HV, height velocity

PICP, carboxyterminal propeptide of type I procollagen

PIIINP, aminoterminal propeptide of type III procollagen

The increased availability of biosynthetic human growth hor-

Received December 3, 1990; accepted March 18, 1991.

Correspondence and reprint requests: Professor A.P. Mowat, Department of Child Health, King's College Hospital, Denmark Hill, London, SE5 8RS, United Kingdom.

Supported by grants from The Children's Liver Foundation (formerly The Michael McGough Foundation Against Liver Disease in Children), The Voluntary Research Trust of King's College Hospital, and The Medical Research Council of The Academy of Finland. mone has raised the possibility of using growth hormone to treat a wide range of conditions in which growth retardation is a feature $(1,2)$. At the present time, the effects of this expensive treatment can only be evaluated by determining HV over several months. Because metabolism of extracellular matrix components increases during growth, measurement of extracellular matrix production may be a biochemical means of monitoring growth. This may be useful in assessing short-term effects of growth hormone and may help to identify at an early stage those children who will respond to growth hormone therapy.

The major structural proteins of the extracellular matrix are the interstitial collagens, of which there are several genetically distinct types. Type I collagen is the most abundant and is found in mineralized bone and soft connective tissues; type III collagen occurs with type $I$ in soft connective tissues, but in lesser amounts, whereas type II collagen is found predominantly in cartilage (3). During the synthesis of these collagens, large soluble propeptide domains are released into the circulation from the precursor procollagen molecules (4). A number of investigations have shown that serum concentrations of the aminopropeptide of type III procollagen, measured by RIA, reflect growth rates (5-9). Because growth hormone has well-established direct effects on bone growth but is without known direct effects on the growth of somatic tissue, it might be anticipated (10) that the serum concentration of PICP may be more useful in assessing growth than PIIINP, because type I collagen is found in both bone and somatic tissues, whereas type III collagen is only found in somatic tissues.

However, studies of PICP have so far been limited to one research group (11-13) with access to an assay developed by Taubman et al. (14). The introduction of a new, easily available assay for PICP (15) prompted the present study to assess the role of serum procollagen propeptides in monitoring growth. Our aim was to define the specificity of the new RIA for PICP, to assess the practicality of using this assay for routine monitoring of pediatric patients, and to establish, for the first time, reference values for serum PICP in healthy infants and children. In addition, we assessed the relationship between serum PICP and HV in untreated growth disorders and in children before and after 3 mo of treatment with exogenous growth hormone. To determine whether serum PICP may be more useful in assessing growth than serum PIIINP (11), PICP and PIIINP were compared in healthy children and patients with growth disorders.

\section{SUBJECTS AND METHODS}

Healthy Infants and Children. 442 healthy white Caucasian subjects between 3 wk and $18 \mathrm{y}$ of age were studied ( 215 females, 
227 males). All were recruited from the local population in southeast England and came to King's College Hospital specifically to donate samples of blood. All were reported by their parents to be healthy and engaged in activities normal for their age. Hematologic parameters and biochemical tests of liver function were within the reference range for age in all subjects. No healthy subject was receiving any drug therapy at the time of blood sampling, but some infants had received diptheria/pertussis/tetanus vaccine up to $3 \mathrm{wk}$ previously. This study had the approval of The Ethical Committee of King's College Hospital, and informed consent was obtained from the parents and, where appropriate, from the children before participation in the study.

The heights and weights of the healthy subjects were all within the reference interval for age. No assessment was made of pubertal stage. The subjects had not fasted and blood was obtained between 1000 and $1200 \mathrm{~h}$ from the antecubital vein with the subject in the sitting position. Serum was separated within 1-3 $h$ of sampling blood, and the samples were batch stored at $4^{\circ} \mathrm{C}$ for up to $48 \mathrm{~h}$ before being assayed for biochemical tests of liver function or at $-70^{\circ} \mathrm{C}$ for $1-3$ y until assayed for PICP and PIIINP. Such storage conditions were found to have a negligible effect on serum biochemical parameters measured.

Patients. 76 children with disorders of growth who had formed part of a cohort in a previous study (7) were assessed. Using diagnostic criteria previously described (7), 38 (31 male; 7 female) had growth hormone insufficiency, 21 (13 male; 8 female) had no endocrinologic abnormality but were of short stature (short normal), and 17 (5 male; 12 female) had tall stature; 14 of the tall subjects were pubertal. Height and HV in the three patient groups are shown in Table 1. Blood samples were obtained from nonfasted patients between 0600 and $0900 \mathrm{~h}$, and the separated serum samples were stored at $-70^{\circ} \mathrm{C}$ for up to 3 y until used for PICP and PIIINP analysis. None of the patients had previously received exogenous growth hormone therapy. Fifteen (five growth hormone insufficient, 10 short normal) started treatment with Somatatrem (Somatonorm:KabiVitrum, Stockholm, Sweden), $2 \mathrm{U}$ per dose s.c. six times per wk) during the course of this study; in these patients, serum PICP and PIIINP were measured both before and at 3 mo after starting treatment with Somatonorm.

Biochemical Analyses of Serum. Assay for PICP. Serum PICP was measured with a recently developed, equilibrium RIA kit (Farmos Diagnostica, Oulunsalo, Finland) (15). We initially tested for whether the antigen related to PICP in the serum of healthy infants and children binds the PICP-antibodies in the RIA with the same affinity as the standard PICP. To determine this, full inhibition curves were run for 15 samples of serum (PICP concentrations 390-2820 $\mu \mathrm{g} / \mathrm{L}$ ), serially diluting each sample with the zero standard provided in the assay kit. All the inhibition curves obtained (mean slope $\pm S D=-1.293 \pm 0.23$ ) were parallel to the standard curve of PICP $(-1.262 \pm 0.28)$, indicating that serum PICP binds in the assay with the same affinity as the standard PICP. Samples of serum from infants

Table 1. Height, HV, and serum PICP and PIIINP in untreated children with growth disorders

\begin{tabular}{lccc}
\hline & $\begin{array}{c}\text { GHI* } \\
(n=38)\end{array}$ & $\begin{array}{c}\text { SN } \\
(n=21)\end{array}$ & $\begin{array}{c}\text { Tall } \\
(n=17)\end{array}$ \\
\hline Height $(\mathrm{cm})$ & $118.8 \pm 12.8 \dagger$ & $113.3 \pm 12.3$ & $170.9 \pm 22.3$ \\
Height-SDS & $-2.24 \pm 0.91$ & $-2.13 \pm 0.59$ & $+3.54 \pm 0.79$ \\
HV $(\mathrm{cm} / \mathrm{y})$ & $3.76 \pm 0.99$ & $5.38 \pm 0.76$ & $6.97 \pm 2.01$ \\
HV-SDS & $-2.16 \pm 1.29$ & $-0.49 \pm 0.49$ & $+1.68 \pm 2.44$ \\
Serum PICP $(\mu \mathrm{g} / \mathrm{L})$ & $240 \pm 90$ & $320 \pm 120$ & $360 \pm 160$ \\
Serum PICP-SDS & $-0.74 \pm 0.69$ & $+0.09 \pm 0.98$ & $+0.26 \pm 1.31$ \\
Serum PIIINP $(\mu \mathrm{g} / \mathrm{L})$ & $5.7 \pm 1.4$ & $6.1 \pm 1.5$ & $10.3 \pm 3.1$ \\
Serum PIIINP-SDS & $-1.08 \pm 0.61$ & $-0.86 \pm 0.56$ & $+0.89 \pm 1.80$ \\
\hline
\end{tabular}

* GHI, growth hormone insufficiency; SN, short normal; Tall, tall stature.

$\dagger$ Values are mean \pm SD and children could therefore be assayed as a single dilution and their PICP concentration read directly from the standard curve.

Serum samples were routinely assayed using duplicate $50-\mu \mathrm{L}$ aliquots of serum diluted with $50 \mu \mathrm{L}$ of the zero standard provided in the assay kit. When serum PICP values were $>350$ $\mu \mathrm{g} / \mathrm{L}$, the samples were further diluted with the zero standard and re-assayed. The sensitivity of the assay was defined as the detectable mass equivalent to twice the SD of the zero binding value and was found to be $1.2 \mu \mathrm{g}(15)$. The interassay coefficients of variation were $5.6,4.5$, and $6.0 \%$ for serum PICP concentrations of 120,432 , and $2107 \mu \mathrm{g} / \mathrm{L}$, respectively; intraassay coefficients of variation were $4.5,5.0$, and $5.6 \%$, respectively. Repeated freeze-thawing of serum and storage at $-70^{\circ} \mathrm{C}$ had a negligible effect on PICP concentrations.

To assess the specificity of the RIA in healthy subjects of different ages, $0.5-1.0 \mathrm{~mL}$ of serum from five subjects (age range 2 mo to $13.5 \mathrm{y})$ were chromatographed on a column $(1.5 \times 110$ $\mathrm{cm})$ of Sephacryl S-300 equilibrated with PBS pH 7.2 containing $0.04 \%$ Tween 20 . Twenty-min fractions were collected at room temperature and directly analyzed for PICP, using the PICP assay in a sequential rather than equilibrium manner to increase the sensitivity. The column was calibrated with purified ${ }^{125} \mathrm{I}-$ labeled PICP. Serum samples $(1.0 \mathrm{~mL})$ obtained from a child with growth hormone insufficiency both before and after 3 mo of growth hormone therapy were similarly chromatographed.

Other biochemical assays. The PIIINP was assayed with a RIA kit (Farmos Diagnostica) as previously described (7).

Biochemical tests of liver function were measured within $48 \mathrm{~h}$ of sampling blood using a Sequential Multiple Analysis with Computer analyzer (Technicon Instrument Corp., Basingstoke, England).

Data Analysis. Serum PICP data in healthy subjects, children with growth disorders, and the two groups together were found to follow a normal distribution. A one-way analysis of variance was used to determine whether a difference existed between healthy subjects of different ages, and the statistical significance of the differences between the mean values was then determined using the $t$ test. The relationships between serum PICP and age, height, and weight in healthy subjects were analyzed using regression analysis.

To compare serum PICP in children with growth disorders directly with age-matched controls, serum PICP in the patients was expressed as a SD score where:

SDS $=\frac{\text { observed PICP }- \text { mean PICP for age-matched controls }}{\text { SD for age-matched controls }}$

A PICP-SDS greater than +2.0 or less than -2.0 showed that PICP was outside the reference interval for age (defined as mean $\pm 2 \times \mathrm{SD}$ ). The difference in PICP-SDS between the three groups of patients was tested using a one-way analysis of variance followed by the $t$ test. The relationship between serum PICP and HV in untreated patients was tested using regression analysis. The paired $t$ test was used to assess the significance of increases in HV, PICP, and PIIINP in children treated for 3 mo with exogenous growth hormone; the correlations were analyzed using regression analysis.

\section{RESULTS}

Distribution of PICP concentrations in serum in infants and children. Serum PICP values showed a normal distribution in healthy infants and children, in patients with growth disorders, and in the two cohorts combined.

Serum PICP in healthy infants and children. In healthy infants and children, there was a marked variation in the concentrations of PICP in serum with age in the first $4 \mathrm{y}$ of life (Fig. 1). The highest values of PICP occurred in infants younger than 3 mo of age (mean $\pm \mathrm{SD}=2200 \pm 350 \mu \mathrm{g} / \mathrm{L}, n=13$ ), decreasing to 1700 $\pm 710 \mu \mathrm{g} / \mathrm{L}(n=20)$ between 3 and $6 \mathrm{mo}, 1040 \pm 480 \mu \mathrm{g} / \mathrm{L}(n$ $=17)$ between 6 and $9 \mathrm{mo}$, and $870 \pm 370 \mu \mathrm{g} / \mathrm{L}(n=15)$ between 


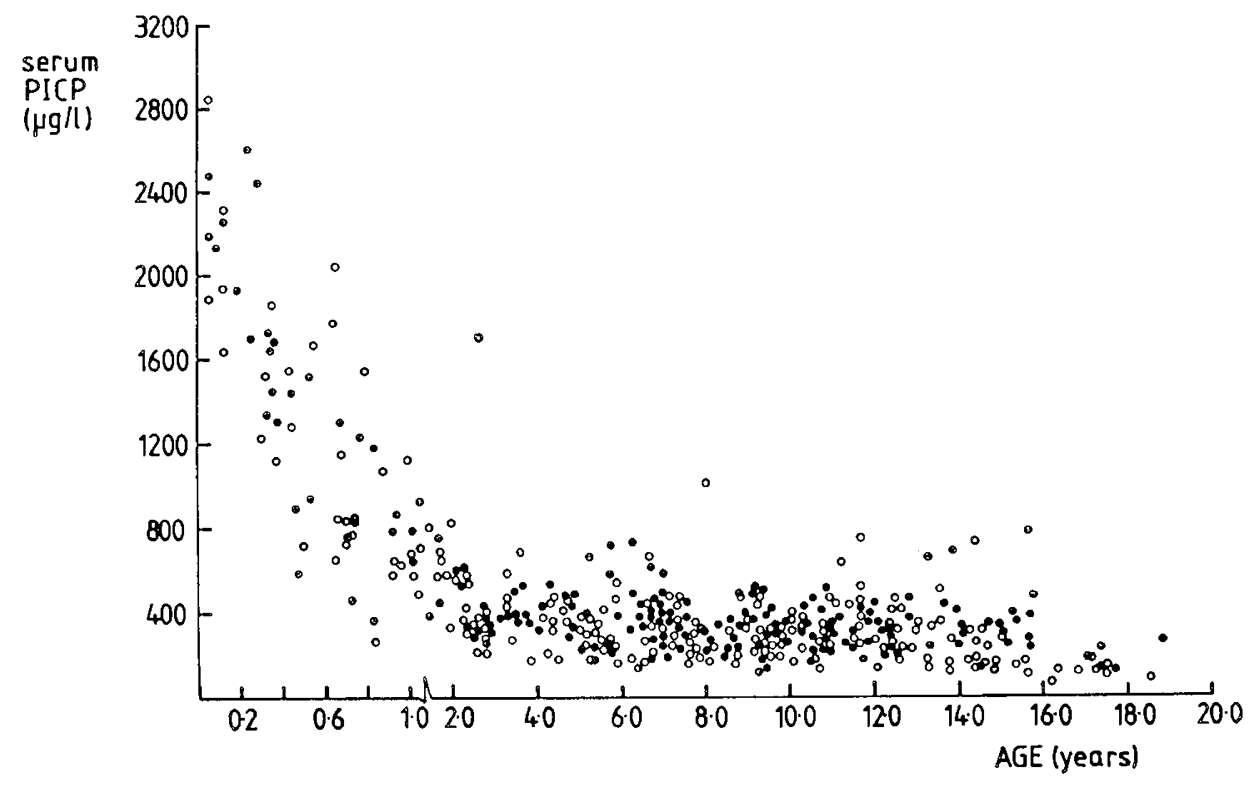

Fig. 1. Serum concentrations of PICP in 441 healthy infants and children. (๑) male subjects; $(O)$ female subjects.

9 and 12 mo. Between 12 and 24 mo, PICP concentration was $670 \pm 170 \mu \mathrm{g} / \mathrm{L}(n=19), 390 \pm 160 \mu \mathrm{g} / \mathrm{L}(n=30)$ between 2 and $3 \mathrm{y}$, and $410 \pm 130 \mu \mathrm{g} / \mathrm{L}(n=15)$ between 3 and $4 \mathrm{y}$. There were significant negative correlations $(p<0.001)$ between PICP and age $(r=-0.865)$, height $(r=-0.879)$, and weight $(r=$ -0.838 ) in the 129 samples obtained during the first $4 \mathrm{y}$ of life. Between 4 and $16 \mathrm{y}$, the PICP concentrations covered a wide range $(330 \pm 130 \mu \mathrm{g} / \mathrm{L})$ but did not fall further. There were a few notably high values (see Discussion), but there did not appear to be any systematic change with age. Adult levels of PICP (generally $<160 \mu \mathrm{g} / \mathrm{L}$; Ref. 12 ), which are significantly lower ( $p$ $<0.001)$ than children's values, were reached by $16-18$ y of age. There was no significant difference between the PICP concentrations in male and female subjects in any age group up to $18 \mathrm{y}$ of age.

To assess the specificity of the PICP assay, five serum samples representing a wide range of PICP concentrations (2320-340 $\mu \mathrm{g} /$ $\mathrm{L})$ and ages ( 2 mo to $13.5 \mathrm{y}$ ) were analyzed by gel filtration on a column of Sephacryl S-300. Only one peak of antigenicity was detected in each sample, and in each case its $M_{r}$ was similar to that of the purified standard PICP.

Serum PICP in children with growth disorders. Children with growth hormone insufficiency had the lowest PICP concentrations in serum; short normal children tended to have somewhat higher values; and tall children had PICP values that covered a wide range (Table 1). In the whole group of 76 patients, serum PICP was related to linear growth, the lowest values being found in children with a $\mathrm{HV}<2.5 \mathrm{~cm} / \mathrm{y}$ and the highest in those with a HV $>7.5 \mathrm{~cm} / \mathrm{y}$ (Table 2). There were significant correlations $(p<0.01)$ between PICP and HV, irrespective of whether they were expressed as absolute values or SDS values (PICP versus HV $r=0.594$, PICP versus HV-SDS $r=0.434$; PICP-SDS versus
HV $r=0.646$, PICP-SDS versus HV SDS $r=0.462$ ). The correlations between serum PICP and HV remained significant $(p<0.01)$, even when the untreated patients were divided into prepubertal (PICP versus HV $r=0.516$ ) and pubertal (PICP versus $\mathrm{HV} r=0.508$ ) groups.

There was considerable overlap in serum PICP values between children with growth hormone deficiency, those with short stature, and tall children, and between these groups and age-matched healthy children (Table 1). When the PICP concentrations were expressed as PICP-SDS (Table 1), none of the growth hormone insufficient children or the short normal children had values of PICP-SDS below the lower limit of normal for age (i.e. less than -2.0), although many did have serum PICP-SDS values within the lower part of the reference interval for age. Two of the tall children had PICP-SDS above the upper limit of normal for age (i.e., above +2.0 ), but the other 10 had values within the normal range for age.

Of the 15 prepubertal children treated for 3 mo with exogenous growth hormone, all showed significant increases $(p<0.001)$ in $\mathrm{HV}$ and concomitant increases in serum PICP. In the 10 who were short normal, $\mathrm{HV}$ increased from $5.3 \pm 0.5 \mathrm{~cm} / \mathrm{y}$ (mean \pm SD) to $8.7 \pm 2.0 \mathrm{~cm} / \mathrm{y}$, with a concomitant increase in the concentration of PICP in serum from $260 \pm 50 \mu \mathrm{g} / \mathrm{L}$ to $440 \pm$ $190 \mu \mathrm{g} / \mathrm{L}$; in the five patients who were growth hormone insufficient, $\mathrm{HV}$ increased from $3.5 \pm 1.7$ to $9.0 \pm 2.2$ and PICP from $200 \pm 90$ to $420 \pm 140$. The absolute values of HV were related to the absolute values of PICP when the samples from the 15 children before and after 3 mo treatment with growth hormone were considered as a single group $(r=0.721, p<0.001, n=30)$. After the 3-mo treatment period with growth hormone, there was a highly significant correlation between the increase in HV and the percentage of increase in serum PICP $(r=0.743, p<$

Table 2. Serum PICP, PIIINP, and HV in untreated children with growth disorders

\begin{tabular}{lcccc}
\hline & $\begin{array}{c}\text { HV }<2.5 \\
(n=6)\end{array}$ & $\begin{array}{c}\text { HV }=2.6-5.0 \\
(n=42)\end{array}$ & $\begin{array}{c}\text { HV }=5.1-7.5 \\
(n=18)\end{array}$ & $\begin{array}{c}\text { HV }=7.6-10.0 \\
(n=7)\end{array}$ \\
\hline HV $(\mathrm{cm} / \mathrm{y})$ & $2.18 \pm 0.45 \dagger$ & $4.21 \pm 0.61$ & $6.02 \pm 0.70$ & $8.48 \pm 0.77$ \\
HV-SDS & $-3.92 \pm 0.71$ & $-1.51 \pm 1.09$ & $+0.10 \pm 1.42$ & $+3.43 \pm 2.04$ \\
PICP $(\mu \mathrm{g} / \mathrm{L})$ & $190 \pm 130$ & $250 \pm 80$ & $320 \pm 140$ & $380 \pm 200$ \\
PICP-SDS & $-1.01 \pm 0.99$ & $-0.62 \pm 0.60$ & $+0.04 \pm 1.12$ & $+0.88 \pm 0.85$ \\
PIIINP $(\mu \mathrm{g} / \mathrm{L})$ & $4.9 \pm 1.4$ & $6.4 \pm 1.8$ & $7.0 \pm 3.0$ & $11.4 \pm 3.3$ \\
PIIINP-SDS & $-1.43 \pm 0.68$ & $-0.63 \pm 0.94$ & $-0.57 \pm 1.52$ & $+1.19 \pm 1.56$ \\
\hline
\end{tabular}

$*$ In $\mathrm{cm} / \mathrm{y}$.

$\dagger$ Values are mean $\pm \mathrm{SD}$. 

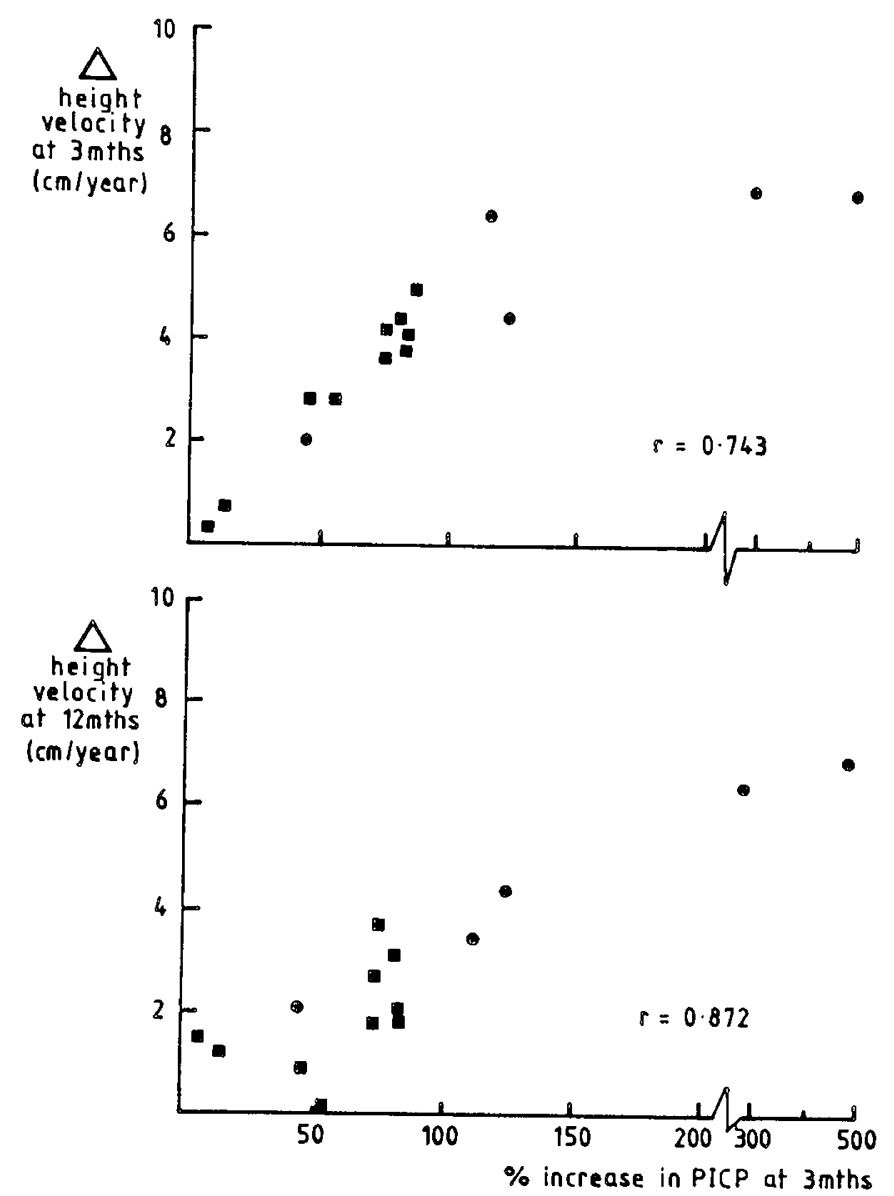

Fig. 2. Percentage of increase in serum PICP after 3 mo of treatment with growth hormone and change in HV after $3 \mathrm{mo}$ and $12 \mathrm{mo}$ of treatment, respectively. (๑) growth hormone insufficiency; ( $\square$ ) short normal.

$0.001, n=15$; Fig. 2): two children (with growth hormone insufficiency) who had disproportionately high-percentage increases in serum PICP had had the lowest baseline (i.e. pretreatment) values of serum PICP. Early increases in serum PICP (i.e. after 3 mo of treatment) were related to the growth response after 1 y of treatment $(r=0.872, p<0.001$; Fig. 2) Baseline PICP concentrations in serum were not related to the increase in growth velocity after either 3 mo or $1 \mathrm{y}$ of treatment with exogenous growth hormone.

Gel filtration studies showed that the serum antigens detected by the PICP assay were similar both before (pretreatment PICP $=87 \mu \mathrm{g} / \mathrm{L}$ ) and after 3 mo of treatment with exogenous growth hormone (PICP $=320 \mu \mathrm{g} / \mathrm{L}$ ). Only one peak of antigenicity for PICP was detected in both samples, corresponding in $M_{r}$ to that of purified PICP.

Relationship between concentrations of PICP and PIIINP in serum. Although the general trend of the PICP results was similar to PIIINP results (14), there were some important differences between PICP and PIIINP.

The pattern of change in serum PICP with age in healthy subjects was similar to that of PIIINP (7) up to $10 \mathrm{y}$ of age, with a significant correlation between serum PICP and PIIINP $(r=$ $0.744, p<0.001)$. Over $10 \mathrm{y}$, there was no apparent systematic increase in PICP, in contrast to PIIINP, which increased significantly around the chronologic age of puberty (14).

In the untreated children with growth disorders, both serum PICP and PIIINP were the lowest in the children with growth hormone insufficiency and the highest in the tall children (Table 1 ); the tall children (most of whom were pubertal) had proportionately greater values of PIIINP when compared to PICP (Table 1). In the 62 prepubertal patients, both PICP and PIIINP corre- lated significantly $(p<0.01)$ with $\mathrm{HV}$ and with each other (for PICP versus $\mathrm{HV}, r=0.516$; for PIIINP versus $\mathrm{HV}, r=0.438$; for PICP yersus PIIINP, $r=0.440$ ). In the 14 pubertal patients, only PICP correlated with HV $(r=0.508 ; p<0.01)$; there was no significant correlation between serum PIIINP and $\mathrm{HV}$ or between PIIINP and PICP, probably because PIIINP was disproportionately high in pubertal patients.

In the 15 prepubertal children treated with exogenous growth hormone, both PICP and PIIINP showed a similar significant relationship to $\mathrm{HV}$, although the $r$ value was lower $(0.60$ versus 0.721 ) and the values more widespread for PIIINP. The percentage of increase in both PICP and PIINP after 3 mo of growth hormone treatment were related to each other $(r=0.662)$, and each was related to the increase in $\mathrm{HV}$ at 3 mo [for a percentage of increase in PICP versus increase in $\mathrm{HV}, r=0.743$ (Fig. 2); for a percentage of increase in PIIINP versus increase in $\mathrm{HV}, r=$ 0.470 ]. The early changes in both PICP and PIIINP (i.e. after 3 mo of growth hormone treatment) were also significantly related to the increase in HV after 12 mo of growth hormone treatment [for a percentage of increase in PICP at 3 mo versus change in $\mathrm{HV}$ at $12 \mathrm{mo}, r=0.872$ (Fig. 2); for a percentage of increase in PIIINP at 3 mo versus change in $\mathrm{HV}$ at $12 \mathrm{mo}, r=0.625]$.

\section{DISCUSSION}

Type I collagen is the most abundant collagen species in the body and is found both in the skeleton and soft tissues (3). During growth, a very active synthesis of type I collagen may be reflected by high serum concentrations of PICP, and, in healthy individuals, serum PICP most probably reflects changes in bone collagen (16). Serum PICP has not, however, been extensively studied because of the lack of a widely available RIA for PICP. The recent development of a new RIA for PICP (15), which is available commercially, makes it feasible to consider the routine measurement of serum PICP in clinical situations in which there is an alteration in growth.

This study confirms that the new PICP assay (15) is simple to perform and highly reproducible, requires only $50 \mu \mathrm{L}$ of sample or less in infants and children, and provides results in less than $6 \mathrm{~h}$. The assay is highly specific, reacting in infants, children, and adults with only one form of serum antigen, that corresponds to PICP, which is released into the circulation during the synthesis of type I collagen. The high specificity of the PICP assay is in contrast to the less specific nature of other assays described for procollagen peptides (17), which have been found to react with heterogeneous forms of serum antigens that may be derived from either synthesis and/or degradation of collagens. The simplicity, high reproducibility, and specificity of the PICP assay make it eminently suitable for routine clinical use.

This study reports, for the first time, reference intervals for serum PICP obtained from a cross-sectional study of 442 healthy white British infants and children. Healthy subjects up to $10 \mathrm{y}$ of age (Fig. 1) showed a pattern of change in serum PICP with age that was generally similar to the pattern of the HV curve for healthy children up to $10 \mathrm{y}(18)$, which suggests that serum PICP is related to growth rate in prepubertal children. However, a few exceptionally high PICP values were observed; recent evidence (Risteli and Risteli, unpublished observations) suggests that the very high serum PICP concentrations occurring in $0.5-1 \%$ of healthy subjects may be due to a polymorphism in the uptake of circulating PICP via the mannose receptor on liver endothelial cells (19).

In addition to similarities in the trends of serum PICP and HV with age in healthy subjects up to $10 \mathrm{y}$ of age, we have also demonstrated a more direct relationship between serum PICP and $\mathrm{HV}$ in untreated prepubertal children with growth disorders and those who received exogenous growth hormone therapy for 3 mo. Particularly in the latter group of patients, the percentage increase in serum PICP over the 3-mo treatment period was closely related to the increase in HV. Although only a relatively 
small group of patients has been studied, these findings strongly suggest that serum PICP is a biochemical marker of growth, as earlier suggested by Carey et al. (11), who also found increases in serum PICP after successful treatment with growth hormone.

However, in some respects our findings are at variance with those of Carey et al., most probably because of differences in the patient groups used. We could find no clear distinction in our study between PICP in children with growth hormone insufficiency and those with short stature but normal endocrinology; PICP showed a continuous distribution between children with growth hormone insufficiency, short stature with normal endocrinology, normal stature, and tall stature, in a manner similar to that seen for other biochemical indices such as insulin-like growth factor. This indicates that measurement of PICP is not of any value in clearly differentiating children with growth disorders from each other or from normally growing children. Also, in contrast to Carey et al. (11), we could find no evidence that the baseline serum PICP concentrations could identify those children who would respond favorably to exogenous growth hormone treatment. We did, however, find that the percentage of increase in serum PICP after 3 mo of growth hormone treatment was related to the increase in HV over $1 \mathrm{y}$ of treatment; whether very early increases in PICP (e.g. after 1 wk of treatment) are similarly predictive of a child's response to growth hormone remains to be investigated in a larger group of patients.

These findings of serum PICP in prepubertal children are very similar to our previous findings with serum PIIINP (7). Graham (10) suggested that serum PICP may be a better marker of linear growth than PIIINP, because PICP reflects bone and somatic growth whereas PIIINP reflects only somatic growth. We have found that, when related to HV, PICP did show higher $r$ values than PIIINP, particularly in the relationship between the percentage of increase in PICP and increase in HV upon treatment with exogenous growth hormone. However, in general, there were significant correlations between serum PIIINP and serum PICP in prepubertal children, showing the self-evident relationship between linear and somatic growth in these patients. A similar relationship between PICP and PIIINP was found in healthy children under $10 \mathrm{y}$ of age.

In healthy subjects over $10 \mathrm{y}$ of age, however, serum PICP and PIIINP appeared to react differently. Unlike PIIINP (7), PICP did not show any systematic increase during the pubertal growth spurts. The wide reference intervals for PICP suggests that there are large interindividual variations in the metabolism of type $\mathbf{I}$ collagen in bone and that any increase in PICP during puberty may, therefore, be masked by the wide reference range in a crosssectional study such as the present one. The increases we previously found in PIIINP during puberty in the same children (7) may be more apparent because of the fairly narrow range of PIIINP found in prepubertal children. Increases in PIIINP may also be more apparent because the serum concentrations of PIIINP reflect the degradation as well as the synthesis of type III collagen, whereas serum PICP reflects only the synthesis of type I collagen. During puberty, an increased degradation of collagens, occurring when tissue remodeling takes place as part of the growth process, may significantly contribute to the PIIINP concentrations in serum but not to serum PICP. This may be why several of our tall pubertal patients had disproportionately high values of serum PIIINP when compared to serum PICP. Future studies using longitudinal measurements are necessary to elucidate the precise pattern of change in serum PICP and PIIINP in different phases of growth (particularly during puberty) in children.

From this study, we conclude that the concentration of the carboxyterminal propeptide of type I procollagen in serum re- flects HV in healthy children under $10 \mathrm{y}$ of age, in prepubertal children with growth disorders, and in those treated with exogenous growth hormone therapy. The development of a specific, simple, rapid, and reproducible RIA for PICP means that serum PICP can now be routinely monitored. Although this RIA had no diagnostic value with regard to growth disorders, it may be a valuable biochemical means of monitoring growth rates. The present study provides some evidence that PICP may be more useful in assessing HV in prepubertal children than PIIINP, but studies in larger groups of children are needed to clarify this. The relationship between serum PICP and PIIINP in puberty may be more complex than previously thought and requires additional longitudinal investigations.

Acknowledgments. Healthy infants and children were recruited through the Medway and Gillingham Branch of The Children's Liver Foundation. The authors thank all subjects and their parents, who cooperated so enthusiastically in this study. We especially thank C. Kerrigan and E. Tresserden for so efficiently organizing the collection of blood from healthy subjects. We also thank Dr P. Cheeseman, King's College Hospital, for invaluable advice and assistance with data analysis.

\section{REFERENCES}

1. Bierich JR 1989 Therapy with growth hormone-old and new indications. Horm Res 32:153-165

2. Milner RDG 1990 Proper use of growth hormone. Arch Dis Child 65:70-71

3. Weiss JB, Jayson MIV 1982 Collagen in Health and Disease. Churchill Livingstone, London, p 6

4. Prockop DJ, Kivirikko KI, Tuderman L, Guzman NA 1979 The biosynthesis of collagen and its disorders. (review) N Engl J Med 301:13-23

5. Lindstedt G, Weijkum LE, Lundberg PA, Albertson-Whitland K 1985 Serum procollagen III as an indicator of therapeutic effect in children treated for somatotrophin deficiency. Clin Chem 11:1879-1880

6. Danne T, Gruters A, Schuppan D, Quantas N, Enders I, Weber B 1989 Relationship of procollagen type III propeptide related antigens in serum in somatic growth in healthy children and patients with growth disorders. J Pediatr 114:257-260

7. Trivedi P, Hindmarsh P, Risteli J, Risteli L, Mowat AP, Brook CGD 1989 Growth velocity, growth hormone concentrations and serum concentrations of the aminopropeptide of type III procollagen. J Pediatr 114:225-230

8. Danne T, Gruters A, Schnabel K, Burger W, l'Allemand D, Enders I, Helge H, Weber B 1988 Long term monitoring of treatment with recombinant growth hormone by serial determination of type III procollagen peptide related antigens in serum. Pediatr Res 23:167-171

9. Tapanainen P, Risteli L, Knip M, Kaar M-L, Risteli J 1988 Serum aminoterminal propeptide of type III procollagen: a potential predictor of the response to growth hormone therapy. J Clin Endocrinol Metab 67:1244-1249

10. Graham MF 1989 The use of serum levels of procollagen propeptides to predict growth velocity. J Pediatr Gastroenterol Nutr 2:143-145

11. Carey DE, Goldberg G, Ratzen SK, Rubin KR, Rowe DW 1985 Radioimmunassay for type I procollagen in growth hormone deficient children before and during treatment with growth hormone. Pediatr Res 19:8-11

12. Hyams JS, Carey DE, Leichtner AM, Goldberg BD 1986 Type I procollagen as a biochemical marker of growth in children with inflammatory bowel disease. J Pediatr 109:619-634

13. Simon LS, Krane SM, Worlman PD, Krane IM, Kovitz KL 1984 Serum levels of Type I and III procollagen fragments in Paget's disease of the bone. J Clin Endocrinol Metabol 58:110-120

14. Taubman MB, Goldberg B, Sherr CJ 1974 Radioimmunassay for human procollagen. Science 186:1115-1117

15. Melkko J, Niemi S, Risteli L, Risteli J 1990 Radioimmunassay of the carboxyterminal propeptide of human type I procollagen. Clin Chem 36:1328 1332

16. Jensen LT, Olesen HP, Risteli J, Lorenzan I 1990 External thoracic ductvenous shunt in conscious pigs for long-term studies of connective tissue metabolites in lymph. Lab Anim Sci 40:620-624

17. Risteli L, Risteli J 1990 Non-invasive methods for detection of organ fibrosis. In: Rojkind M (ed) Focus on Connective Tissue Research in Health and Disease, Vol 1. CRC Press, Boca Raton, pp 61-98

18. Tanner JM, Whitehouse RH, Takishi M 1966 Standards from birth to maturity for height, weight, height velocity and weight velocity: British children Part II. Arch Dis Child 41:613-635

19. Smedsrod B, Melkko J, Risteli L, Risteli J 1990 Circulating carboxyterminal of type I procollagen is cleared mainly via the mannose receptor in liver endothelial cells. Biochem J 271:345-350 